\title{
A NEGOCIAÇÃO DE SIGNIFICADOS EM UMA REUNIÃO DO MOVIMENTO NACIONAL DE MENINOS E MENINAS DE RUA
}

\author{
(Meaning negotiation in a meeting of the National Street \\ Children Movement in Brasília, Brazil)
}

\author{
Viviane de Melo Resende ${ }^{1}$ \\ (Universidade de Brasília - UnB)
}

\begin{abstract}
In this paper, I analyze excerpts of a meeting in the National Street Children Movement (Movimento Nacional de Meninos e Meninas de Rua, MNMMR) that I attended as part of the study "Critical Discourse Analysis and Ethnography: the National Street Children Movement, its crisis and the youth protagonism". The meeting was held in March 2006 and was directed to the national assembly of MNMMR, which would take place a few days after the meeting. Based on Critical Discourse Analysis (Fairclough, 2003), I analyze the negotiating of the meaning of 'youth protagonism', a key concept in this social movement, relating it to the scales of the Movement's action.
\end{abstract}

Keywords: social movement, protagonism, critical discourse analysis, interaction.

1. Mestre e doutora em Linguística pela Universidade de Brasília, é professora na mesma universidade. Na graduação, atua no curso de Letras em disciplinas ligadas à produção de texto. No Programa de Pós-Graduação em Linguística, ministra disciplinas em análise de discurso crítica. Tem diversos artigos publicados em periódicos nacionais e internacionais. É autora dos livros Análise de Discurso Crítica e Realismo Crítico: implicações interdisciplinares (Campinas: Pontes, 2009) e Análise de Discurso Crítica (com Viviane Ramalho; São Paulo: Contexto, 2006). Recentemente, organizou, com o jornalista Fábio H. Pereira, o livro Práticas socioculturais e discurso: debates transdisciplinares (Covilhã: Labcom, 2010). 


\section{RESUMO}

Neste artigo, analiso trechos de uma reunião do Movimento Nacional de Meninos e Meninas de Rua (MNMMR) de que participei como parte da pesquisa "Análise de Discurso Crítica e Etnografia: o Movimento Nacional de Meninos e Meninas de Rua, sua crise e o protagonismo juvenil" (Resende, 2008). A reunião, realizada em março de 2006, foi direcionada à assembleia nacional do MNMMR, que aconteceria dias depois. Com base na Análise de Discurso Crítica (Fairclough, 2003), analiso a negociação do significado de 'protagonismo juvenil', um conceito fundamental para esse movimento social, relacionando-o às escalas de atuação do Movimento.

Palavras-chave: movimento social, protagonismo, análise de discurso crítica, interação.

\section{Introdução}

Neste trabalho, dedico-me à análise de recorte de uma reunião do Movimento Nacional de Meninos e Meninas de Rua (MNMMR) de que participei como parte da pesquisa "Análise de Discurso Crítica e Etnografia: o Movimento Nacional de Meninos e Meninas de Rua, sua crise e o protagonismo juvenil” (Resende, 2008). Essa pesquisa, realizada entre 2005 e 2008, teve carater multimetodológico e, em termos da teoria do funcionamento social da linguagem e do método para análise de dados, baseou-se nos pressupostos da Análise de Discurso Crítica (Chouliaraki \& Fairclough, 1999; Fairclough, 2003; Resende \& Ramalho, 2006).

A reunião de que trago um recorte neste artigo realizouse em março de 2006 e foi voltada para a assembleia nacional do MNMMR, que se realizaria dias depois. Focalizou o debate em torno da descentralização do Movimento, em contexto de crise da entidade (veja a seguir). No recorte da reunião transcrita, analiso pontos de instabilidade acerca do conceito de protagonismo juvenil e das escalas de atuação do Movimento. Reflito, também, sobre os lugares dos sujeitos na interação, as assimetrias interpessoais e suas implicações discursivas, em termos de modalidade objetiva/subjetiva. 


\section{O Movimento Nacional de Meninos e Meninas de Rua}

Movimentos sociais são definidos como "ações sociais coletivas de caráter sociopolítico e cultural que viabilizam distintas formas de a população se organizar e expressar suas demandas" (Gohn, 2003b: 13). Para Pasquino (2004: 787), os movimentos sociais "constituem tentativas, fundadas num conjunto de valores comuns, destinadas a definir formas de ação social e influir em seus resultados”. Assim, o significado de movimentos sociais está associado à mobilização da sociedade civil e à crença na capacidade de atores sociais, engajados em ação coletiva, influenciarem no sentido da mudança social.

Castells (1999) e Gohn (2003a) concordam que a emergência de movimentos populares urbanos deu-se nas décadas de 1970 e 1980 , quando "os movimentos urbanos estavam se tornando as principais fontes de resistência à lógica unilateral do capitalismo” (Castells, 1999: 80). No que se refere à mobilização voltada para a questão de crianças e adolescentes em situação de rua, Santos (1994) localiza o surgimento de um movimento de oposição à concepção assistencialista e repressora no tratamento da infância e da adolescência no Brasil no final da década de 1970. Segundo ele, em resposta a esse enfoque que "atua retirando as crianças e adolescentes do meio em que vivem para colocá-las em instituições fechadas de recuperação” e cujo modelo é "autoritário pois não permite - nem muito menos estimula - a participação da população na gestão da política para a infância e adolescência", formou-se uma abordagem participativa, que "centrase na criação de condições para que as crianças e adolescentes descubram soluções alternativas para seus próprios problemas" (Santos, 1994: 11). Este modelo é fundamentado na participação da sociedade, e a ação voltada para as crianças e adolescentes é realizada no próprio ambiente em que vivem. Esse novo enfoque teve inspiração nos trabalhos desenvolvidos pela Pastoral do Menor e pelo Movimento de Defesa do Menor.

O ano de 1979 foi proclamado, pela Organização das Nações Unidas, o Ano Internacional da Criança. No Brasil, durante esse ano realizaram-se campanhas, seminários e debates que difundiram 
a problemática da situação de crianças no país. Essa interlocução difundiu também o papel da educação social de rua como alternativa ao modelo repressor e assistencialista no que se refere a crianças e adolescentes em situação de rua. Como resultado, configuraram-se diversas iniciativas com propostas alternativas para o tratamento do problema da vulnerabilidade de crianças e adolescentes no Brasil.

Esses diversos movimentos populares isolados tiveram a oportunidade de se organizar em rede por meio do Projeto Alternativas Comunitárias de Atendimento a Meninos de Rua, implantado em 1982 com o apoio do Fundo das Nações Unidas para a Infância. A articulação em rede é, para Castells (1999), um fator fundamental para a capacidade de os movimentos sociais configurarem-se atores políticos com influência nas tomadas de decisão. A interlocução entre as iniciativas então existentes no país, engajadas na construção de alternativas, resultou na formação, em 1985, de um movimento social articulado em rede.

Nesse primeiroanode sua existência, oMNMMR foi batizadocomo Movimento Nacional de Alternativas Comunitárias de Atendimento a Meninos de Rua, marcando sua posição como concepção alternativa ao modelo assistencialista e repressor em vigência, materializado no Código de Menores, lei de 1979. No Encontro Nacional de Grupos Locais, realizado em Brasília em 1985, foram traçadas as diretrizes para a constituição do Movimento e foi eleita uma Comissão Nacional com dez membros, dois de cada região do país.

Em maio de 1986, esse movimento recém fundado foi capaz de organizar o I Encontro Nacional de Meninos e Meninas de Rua, com a participação de cerca de 500 crianças e adolescentes de todas as regiões do Brasil: "este encontro, inédito em todo o mundo, desperta a atenção da sociedade e transforma-se em um marco significativo para que meninos e meninas de rua comecem a adquirir voz e vez e iniciem um processo de organização para lutar contra a violência e pelos seus direitos de cidadania" (Santos, 1994: 14). Em agosto do mesmo ano, na II Assembleia Nacional do Movimento, seu estatuto foi aprovado e o Movimento Nacional de Meninos e Meninas de Rua foi oficialmente constituído. 
Entre 1986 e 1988, foram formadas comissões locais na maior parte dos estados brasileiros, e foram estruturadas comissões regionais nas cinco regiões geográficas do país e a secretaria nacional com sede em Brasília. Por meio da articulação em rede, o MNMMR foi capaz de ultrapassar seu papel reivindicatório para assumir também um papel propositivo, de acordo com a configuração dos novos movimentos sociais discutida por Gohn (2003b: 24):

os movimentos populares criaram, ou ampliaram, ou fortaleceram a construção de redes sociais. (...) As identidades coletivas dos movimentos populares deixaram alguns elementos de lado, tais como as freqüentes contestações às políticas públicas, mas como eles incorporaram outros elementos, isso possibilitou-lhes sair do nível apenas reivindicatório, para um nível mais operacional, propositivo. (...) Não se tratava mais de ficar de costas para o Estado, mas de participar das políticas, das parcerias etc. Eles ajudaram a construir outros canais de participação, principalmente os fóruns; e contribuiram para a institucionalização de espaços públicos importantes, tais como os diferentes conselhos criados nas esferas municipais, estaduais e nacional.

Nesse sentido, o Movimento participou da criação do Fórum Nacional Permanente de Entidades Não-Governamentais de Defesa dos Direitos da Criança e do Adolescente, em 1988. Por meio de sua participação ativa no Fórum DCA, “o MNMMR participou do processo de elaboração da Constituição Federal, fazendo lobby junto a deputados e senadores constituintes. Esse trabalho resultou na inclusão dos artigos 227 e 228 na Constituição. O Movimento participou também da elaboração do anteprojeto do ECA” (Santos, 1994: 16).

Embora nunca tenha abandonado seu papel de denúncia, o MNMMR articula também papéis de pressão reivindicatória direta (como as marchas de 18 de maio, Dia Nacional de Enfretamento à Violência Sexual contra Crianças e Adolescentes) e indireta, como nos casos em que fez lobby junto ao Congresso Nacional para a aprovação do Estatuto da Criança e do Adolescente - ECA (em 1990) e para a criação do Conselho Nacional dos Direitos da Criança e do Adolescente - Conanda (em 1991), ou como ainda tem feito contra o 
rebaixamento da maioridade penal. Por seu trabalho junto a crianças e adolescentes em situação de rua, o Movimento recebeu, em 1991 e em 1992, prêmios nacionais e internacionais.

Apesar da configuração em rede e da participação de militantes do Movimento nos conselhos de direitos, e também nos conselhos tutelares, outros elementos da configuração do MNMMR afastam-no da caracterização dos novos movimentos sociais: a profissionalização de seus membros e a utilização dos novos meios de comunicação.

Em sua discussão sobre os novos movimentos sociais, Gohn (2003b: 30) sugere que "a nova fase gerou práticas novas, exigiu a qualificação de militantes, por isso é grande o número de militantes/ assessores de movimentos que têm entrado nos programas de pósgraduação da academia". No MNMMR, ao contrário, "os educadores voluntários, militantes e ativistas dos direitos da criança e do adolescente engajados nas comissões locais, na sua maioria, têm escolaridade entre os graus primário e secundário; apenas uma pequena parcela tem formação universitária” (Santos, 1994: 24). Na Comissão Local do DF essa informação continua sendo verdadeira: em 11 de abril de 2006, depois de conversa com a educadora Vera ${ }^{2}$ na sede da Comissão Local do DF, registrei em meu diário de campo: "A Vera disse que nenhuma ONG trabalha mais com educadores/ as de nível médio, todo mundo investiu na capacitação de seus/ suas educadores/as, mas o Movimento ficou para trás por falta de recursos". À falta de qualificação formal soma-se a desarticulação dos espaços institucionais de formação.

Em relação à utilização dos novos meios de comunicação para a articulação mais efetiva da rede, aspecto fundamental dos movimentos sociais de maior impacto na atualidade segundo Castells (1999), o MNMMR não utiliza com eficácia as ferramentas de comunicação disponibilizadas pela Internet. Ainda que as comissões locais disponham de computadores conectados à Internet, e ainda que as mensagens eletrônicas sejam utilizadas para comunicação entre as comissões do Movimento e sua iniciativa nacional, outros recursos não

2. Todas as referências a participantes da pesquisa são feitas por meio de pseudônimos. 
são bem explorados. Por exemplo, o Movimento não dispõe de um site atualizado, não utiliza a Internet para divulgar suas atividades e não explora os recursos disponíveis para teleconferências, o que poderia ter resultados positivos para a integração dos trabalhos desenvolvidos pelas diversas comissões e para a visibilidade do Movimento.

Esse aspecto, ligado às tecnologias de comunicação, pode estar relacionado à atual desarticulação da rede nacional do Movimento, observada em minha pesquisa de campo. A desarticulação nacional do Movimento foi tema debatido na Assembleia Nacional de que participei em abril de 2006, e sobre a qual tomei as seguintes notas de campo:

Houve consenso de que o Movimento precisa de estratégias de comunicação para divulgar seu trabalho. Disseram na Assembléia que houve um tempo em que o Movimento tinha 'cabeça na estrutura nacional' e não tinha 'corpo nos estados', mas que agora a situação se inverteu: tem corpo nos estados, mas não tem estruturação nacional eficiente (Notas de campo registradas em $1^{\circ}$ de abril de 2006).

Assim, ao contrário do que Gohn (2003b) define como característica dos novos movimentos sociais, no caso do MNMMR em vez de uma maior integração em rede o que se observou foi um enfraquecimento da rede anteriormente existente. A sensação predominante na assembléia de 2006 foi a inexistência de um movimento propriamente nacional, mas sim de diversos movimentos locais que representam essa iniciativa nacional.

O foco de ação do Movimento durante o tempo em que realizei a pesquisa era a conscientização de crianças e adolescentes atingidos/ as pela vulnerabilidade social, que se encontram em situação de risco devido a sua localização desprivilegiada na distribuição de recursos materiais e simbólicos na sociedade, não necessariamente em situação de rua. Esse alargamento do conceito de 'meninos e meninas de rua' a que se refere o próprio nome do Movimento parece ser mais presente hoje que na época de sua formação, quando as ações da organização eram mais especificamente voltadas para 
esse público. Entretanto, já no início da década de 1990, Fregnani (1992: 6) ressaltou:

O nome 'Movimento Nacional de Meninos e Meninas de Rua' existe desde sua criação, em 1985. Tem a 'rua' no nome do Movimento porque de início a discussão e a ação maior foi em torno dessa situação: meninos e meninas que moram nas ruas. Essa é a pior das situações que vivem as crianças do Brasil. Mas se formos ao fundo da questão, o problema são as desigualdades e as injustiças que todos vivem no país, e se não fizermos alguma coisa, mais crianças estarão nas ruas.

O conceito de 'meninos e meninas de rua' adotado hoje pelo Movimento, então, é amplo: ultrapassa o senso comum de que pertencem a essa categoria apenas crianças e adolescentes que vivem nas ruas ou tiram dela seu sustento, para abarcar também aqueles/as de famílias extremamente pobres. Isso porque essas crianças e adolescentes encontram-se constantemente em situação de risco, inclusive o risco de rua, devido ao contexto de precariedade socioeconômica em que se situam. Essa ampliação do foco não é vista, entretanto, como uma questão simples. Ao contrário, é problemática no Movimento, pois não se trata apenas de uma ampliação do foco o que significaria o trabalho simultâneo com crianças e adolescentes efetivamente em situação de rua $e$ com crianças e adolescentes em outras situações de vulnerabilidade -, mas de uma mudança de foco: as comissões locais, de um modo geral, passaram a trabalhar em núcleos de base nas periferias e não nas ruas. Essa questão foi debatida na Assembleia Nacional do Movimento de que participei em abril de 2006, ocasião em que anotei em meu diário de campo: "A questão do trabalho com crianças e adolescentes efetivamente em situação de rua parece ter sido abandonada em todas as comissões locais! Essa é uma grande preocupação da Paula [então coordenadora da Comissão Local do MNMMR no DF]”. Essa questão também foi tratada em outros dados da pesquisa, em que a interrupção do trabalho de educação social de rua foi considerada 'perda do eixo' do Movimento, como na reunião que analiso aqui. 


\section{A pesquisa com o Movimento Nacional de Meninos e Meninas de Rua}

A pesquisa de que neste artigo apresento um recorte focalizou sobretudo representações e identificações por parte das educadoras do MNMMR e de jovens engajadas no trabalho da instituição, consideradas protagonistas juvenis. A investigação empírica dessas questões discursivas foi feita por meio de dados etnográficos, e meu objetivo foi investigar algumas das causas discursivas da crise desse movimento social, empiricamente constatada e confirmada em representações de seus membros.

Não há muitas pesquisas sobre movimentos sociais em ADC, mas se percebemos que a desmobilização da sociedade civil na atual fase do capitalismo é um problema que tem efeitos na manutenção de injustiças, então a relevância de pesquisas junto a movimentos sociais torna-se clara. Especialmente quando se trata de movimentos sociais que enfrentam crises, como foi o caso na pesquisa com o MNMMR.

Em termos metodológicos, a pesquisa buscou estabelecer diálogo entre o paradigma etnográfico de pesquisa qualitativa e os estudos discursivos críticos, especialmente a ADC de Fairclough. A etnografia é definida como uma tradição de pesquisa que agrupa a análise de dados empíricos gerados e coletados sistematicamente para a pesquisa, provenientes de contextos situados e de uma variedade de métodos, embora o foco deva ser relativamente estreito em escala (Hammersley, 1994). Em etnografia, não se objetiva uma generalização por meio dos dados, mas a focalização de práticas particulares em eventos particulares - daí a adequação desse tipo de pesquisa a projetos que, como o que trato aqui, focalizam perspectivas localizadas. Pesquisas etnográficas têm uma preocupação habitual com o particular, com a compreensão da experiência social situada, seus processos e mudanças, sensíveis ao fato de que "processos sociais são contingentes a contextos específicos, e neles encaixados” (Mason, 2006: 17).

Reconhecendo meu interesse por esse movimento específico, e vinculando minha pesquisa a esse contexto particular, objetivei 
compreender a negociação de significados entre seus membros e os modos como esses significados configuram, ao mesmo tempo, produto e meio dos processos de ação social, influenciando os modos de identificação, as relações sociais e a própria ação do Movimento. Para tanto, fiz uso de diversos métodos para geração e coleta de dados, visando explorar diferentes dimensões do objeto da pesquisa. Os métodos utilizados foram a observação participante, as notas de campo, os grupos focais, as entrevistas focalizadas e a gravação de reuniões.

A gravação de reuniões não estava no desenho inicial da pesquisa. Aproveitei as ocasiões, entretanto, para coletar dados, de acordo com o que Retamozo (2006: 11) sugere ao afirmar que "ao estudar movimentos sociais, é preciso pôr em prática uma vigilância etnográfica para identificar situações que possam brindar material para uma melhor compreensão”. Uma vantagem da utilização desses dados é seu potencial para a análise da atividade do Movimento, uma vez que não se trata de dados gerados em situação específica de pesquisa - como são os dados gerados por meio de entrevistas, por exemplo -, mas dados relativos à atividade concreta da própria organização (Resende, 2009).

\section{A reunião}

Durante o trabalho de campo, em diversas ocasiões fui convidada a participar de eventos e atividades do MNMMR, como a Assembleia Nacional, reuniões na sede da Comissão Local, produção de projetos, mobilizações, manifestações, oficinas. Sempre que me foi possível, respondi positivamente aos convites, comparecendo aos eventos para os quais gentilmente me convidavam, sabendo de meu interesse nas práticas da organização.

Em algumas ocasiões, não julgava adequado efetuar gravações em áudio das interações de que participava, por exemplo na Assembleia Nacional e na reunião do Fórum DCA (Fórum Nacional Permanente de Entidades Não-Governamentais de Defesa dos Direitos da Criança e do Adolescente), por estarem presentes pessoas que não 
sabiam/não participavam de minha pesquisa ou por a situação não ser favorável a gravações. Nesses casos, apenas tomei notas.

Duas reuniões, entretanto, puderam ser gravadas. A primeira, esta cujo recorte analiso aqui, foi uma reunião interna da Comissão Local do MNMMR/DF. Participaram dessa reunião a então coordenadora do MNMMR/DF, Paula, Júlia e Vera, educadoras do Movimento, Maria, uma jovem protagonista, e Marcelo, um militante voluntário, formado em Direito e membro também da Renap - Rede Nacional de Advogados Populares. Na pauta dessa reunião estavam a crise financeira do Movimento; a Assembleia Nacional, que ocorreria dias depois; o encerramento das atividades dos núcleos de base. Foi uma reunião tensa, pois a pauta girava em torno da situação de desestruturação da organização, em nível local e nacional.

Assim, a reunião cujo recorte apresento neste artigo ocorreu em contexto de profunda crise, de início das atividades de 2006 tendo sido 2005 um ano particularmente difícil para o MNMMR/ DF, pelo encerramento das atividades de nucleação, considerada uma das principais atividades da organização. Sobre esse agravamento da crise, registrei em minhas notas de campo minha impressão de uma conversa que tive com Vera:

Fui ao Movimento à tarde. A Jú não estava; passou mal e foi pra casa. Falei com a Vera. Ela disse que os últimos três anos foram os piores do Movimento, que o Movimento está passando por uma crise severa, só tem um projeto atualmente. Ela disse que o problema não é só questão de recurso, há também um problema grave de metodologia. Outro problema sério do Movimento para a Vera é a falta de militantes. O Movimento é uma organização de militância, de luta pela crença na possibilidade de mudança, mas hoje quase não há militantes de verdade. Ela usou uma metáfora interessante para definir o agravamento da crise: "se ano passado o Movimento tava capenga, esse ano tá sem perna" (Nota de campo registrada em 9 de fevereiro de 2006).

A reunião aconteceu em 28 de março de 2006, uma terça-feira. No fim de semana seguinte, em Brasília, seria realizada a Assembleia Nacional do MNMMR, com a participação de representantes dos diversos estados do Brasil onde há comissões locais do Movimento. Essa 
assembleia realizou-se sob a tensão da necessidade de descentralização do MNMMR, tendo em vista o problema com o CGC único, que inviabilizava a captação de recursos tanto pela iniciativa nacional do Movimento quanto pelas iniciativas locais. ${ }^{3}$

A análise da reunião está centrada no debate realizado em torno das posições que a Comissão Local do DF levaria à assembleia. No recorte da transcrição da reunião, analiso pontos de instabilidade entre perspectivas de Júlia e de Marcelo. Discordam sobre diversos aspectos da atuação do Movimento - as escalas de atuação, o conceito de protagonismo, o significado de ação política no âmbito do Movimento.

A utilização da gravação da reunião como dado teve seu mérito na pesquisa: permitiu-me conhecer a negociação de significados em conflito no interior do Movimento e alguns pontos de instabilidade em termos de seus focos de atuação. Antes de iniciar a análise sobre a negociação desses pontos de discordância, é preciso refletir sobre os lugares dos sujeitos na interação. Júlia posiciona-se como educadora do Movimento com a experiência de mais de uma década de trabalho na garantia de direitos de crianças e adolescentes; Marcelo, por outro lado, é um jovem militante que precisa negociar o valor de suas perspectivas na interação. É relevante notar como se posiciona cada qual em relação a seu próprio ponto de vista, em termos de modalidade objetiva/subjetiva. É o que veremos na próxima seção.

\section{Modalidade}

A distinção entre modalidade objetiva e subjetiva refere-se ao enlace entre a pessoa que fala e aquilo que fala, em termos específicos

3. Na entrevista que me concedeu, a educadora Júlia explicou-me: "A história do CGC foi o seguinte. Uma comissão, no Mato Grosso do Sul (...) executou um projeto em parceria com o Estado, que era de capacitação dos adolescentes, parecido com o [Programa] Primeiro Emprego. E foi uma má gestão isso. Até por inexperiência e tudo. Houve um uso do Movimento indevido. (...) Então, e aí, foi denunciado no Ministério Público. (...) Desde então, a gente tem problema para aprovar projetos porque o CGC é único”. O resultado desse episódio envolvendo mau uso de recurso público no âmbito do Movimento é que as diversas comissões locais enfrentaram problemas para captar recursos. 
da fonte subjetiva das proposições. Na modalidade objetiva, a base subjetiva do julgamento está implícita: não fica claro qual o ponto de vista privilegiado na representação, se "o falante projeta seu ponto de vista como universal ou age como veículo para o ponto de vista de um outro indivíduo ou grupo" (Fairclough, 2001: 200). Na modalidade subjetiva, por outro lado, a base subjetiva para o grau de afinidade com a proposição é explicitada, deixando claro que a afinidade expressa é do/a próprio/a falante.

As posições de Júlia são pouco modalizadas em termos de modalidade subjetiva, ao passo que Marcelo recorre a orações modalizadas para introduzir seus pontos de vista. Enquantro Júlia utiliza apenas uma vez uma oração com 'eu acho', sendo todas as suas outras intervenções marcadas por modalidade objetiva, Marcelo recorre a essa mesma estrutura linguística quatro vezes, agregando também outras estratégias que podem ser interpretadas como uma negociação de seu espaço no evento discursivo. Vejamos, no excerto (1), as ocorrências de 'eu acho':

(1) Marcelo: Eu acho que a gente poderia iniciar a fala tentando trazer isso: o que é o escritório do Distrito Federal em termos de Movimento porque acaba acontecendo isso, a gente acaba fazendo análise de conjuntura nacional, fica fazendo análise social nacional e não faz o regional, que a gente que passa batendo na tecla, que os caras acham que Brasília, que aqui é para a gente ficar pensando os problemas do Congresso Nacional. [...]

Júlia: Mas eles não estão preocupados com isso não. $E u$ acho que o principal problema não é nem a confusão, por exemplo. Porque isso é uma confusão política mesmo. E também de interesse nosso mesmo. [...]

Marcelo: (...) E, às vezes, a gente ia, ia só ficar com esses protestos, e acaba que não traz a discussão para cá. E acho importante, por exemplo... Tia Jú, eu entendo que a gente não está formando aqui como miliante em quantidade. Mas, que o guri, no momento em que ele passa a ter uma 
oficina nossa, daqui a pouco ele visualiza dentro de uma discussão do passe livre, ele, por pernas próprias, vá até lá e vá porque ele teve uma formação. [...]

Júlia: A formação do Movimento não é uma formação política. É uma formação pedagógica. É uma formação integral, não é só política.

Marcelo: Mas deveria ser.

Júlia: Não deveria.

Marcelo: Não, é uma opinião pessoal. Eu acho que deveria sim.

Júlia: Então nós temos que discutir os nossos princípios. Marcelo: Eu acho que deveria sim. Me desculpa. Porque a gente pensa em programar o mundo social, mundo mais social, mundo socialista e não discute politicamente. Este é grande problema. [...]

Marcelo: (...). E uma coisa que eu acho que é o que está afundando na questão da criança e do adolescente é que a gente só repete o Estatuto da Criança e do Adolescente.

Na primeira fala de Marcelo, além da modalidade subjetiva com 'eu acho', ele lança mão de uma modalidade deôntica com verbo modal e tempo hipotético ("poderia”), expressando sua opinião acerca do posicionamento da Comissão Local do DF na Assembleia Nacional com o caráter de uma possibilidade. Ademais, seleciona uma estrutura verbal mitigada para sua proposta - "tentando trazer" ao invés de 'trazendo' por exemplo. Outras locuções verbais com gerúndio e com o verbo 'acabar' utilizado como auxiliar são observadas em sua representação dos problemas que precisariam ser postos em pauta na assembleia "porque acaba acontecendo isso, a gente acaba fazendo análise de conjuntura nacional” - o que tem o efeito de sugerir uma causação indefinida para os problemas mencionados, desresponsabilizando quaisquer membros do Movimento pelos fatos representados como problemáticos. 
A segunda ocorrência da modalidade subjetiva 'eu acho' acontece na fala de Júlia. Ao contrário do observado em Marcelo, Júlia utiliza essa estrutura ao lado de elementos que fortalecem o valor de verdade de suas proposições. Para começar, sua discordância com o exposto por Marcelo é marcada na adversativa por meio da qual inicia sua intervenção e pela dupla negação ("Mas eles não estão preocupados com isso não"). Em seguida, na oração iniciada por 'eu acho', Júlia novamente utiliza dupla negação, desconstruindo o problema levantado por Marcelo. Nas duas orações seguintes, marca alta afinidade com suas próprias proposições utilizando 'mesmo' em ambas as orações, o que fortalece o valor de verdade de seu ponto de vista acerca da questão do papel da Comissão Local do DF no Movimento.

Marcelo volta a utilizar '[eu] acho', marcando a natureza subjetiva de sua afirmação, quando trata a questão do protagonismo no âmbito do Movimento. Dessa vez, paralelamente a '[eu] acho' recorre à mitigação de 'às vezes' - que aqui não apresenta aspecto de frequência, significando algo como 'talvez'. Outra vez utiliza também uma oração com o verbo 'acabar', assim como em sua primeira intervenção no excerto. É importante notar nesse trecho que Marcelo, antes de introduzir sua discordância com 'mas', busca um elemento de consenso sobre o qual construir seu posicionamento: retoma a fala de Júlia introduzindo-a com "eu entendo".

Em seguida instaura-se um conflito mais direto entre ambos. Ainda que flexione o verbo num tempo hipotético, Marcelo utiliza um verbo modal de obrigatoriedade, marcando com clareza seu ponto de vista dissonante em relação ao de Júlia quando aborda a questão da política no âmbito do Movimento ("Mas deveria ser"), ao que Júlia responde prontamente ("Não deveria"). Em resposta aparece a oração modalizada com 'eu acho', que apresenta outro elemento de modalidade subjetiva, esclarecendo a natureza pessoal de seu posicionamento ("é uma opinião pessoal"). Dessa vez Marcelo lança mão de um recurso de fortalecimento de seu ponto de vista quando agrega um 'sim' ao final da oração. A mesma oração é repetida após a resposta de Júlia ("Eu acho que deveria sim"), mas agora seguida de um pedido de desculpas. 
A descrição dos casos de ocorrência de 'eu acho' no recorte da reunião mostra que, na negociação do dissenso entre Júlia e Marcelo, ela é muito mais assertiva, marca sua posição e sua autoridade. Ele, por outro lado, procura mitigar a discordância, busca pontos de consenso e texturiza os pontos de conflito em orações modalizadas, reconhecendo a autoridade de Júlia. Isso evidencia uma relação hierárquica que influencia os modos como se constrói o debate e como se negociam as diferenças.

\section{Pontos de instabilidade: negociação}

Quanto aos pontos de instabilidade identificados no recorte, uma primeira questão problemática levantada refere-se ao significado de protagonismo juvenil. A análise do significado de uma dada palavra ou expressão em um texto é a análise de como "os sentidos das palavras entram em disputa dentro de lutas mais amplas" (Fairclough, 2001: 105). A lexicalização de significados é construção social, no sentido de que são socialmente negociados e contestados. Embora a expressão 'protagonismo juvenil' apareça no recorte uma única vez, há um debate sobre seu significado, em termos do que significa ou deveria significar o protagonismo na experiência de um/a adolescente ou jovem. Vejamos o excerto (2):

(2) Júlia: Mas eles não estão preocupados com isso não. Eu acho que o principal problema não é nem a confusão, por exemplo. Porque isso é uma confusão política mesmo. E também de interesse nosso mesmo. Porque, por exemplo, quando a gente participava, qual é a nossa proposta? Não era de que os meninos fossem intervir. A proposta dos meninos era dos meninos experimentarem o protagonismo juvenil e que os meninos pudessem vivenciar esse ator político. Então, por isso que a gente participava das manifestações nacionais. Por quê? Como espaço de participação. Muitas vezes, a gente, ora, já foi na marcha do 
MST com os meninos, na marcha da educação, mas como exercício da cidadania, para aprender isso. Tanto faz a gente aprender isso na marcha do MST, como aprender aqui na Câmara Legislativa. Para nós, era indiferente isso. Isso era uma questão metodológica.

Marcelo: Mas o protesto nacional pode acontecer, mas tu tem que trazer ele para o teu estado também.

Júlia: Nem sempre você consegue trazer.

Marcelo: Eu sei que não! Mas essa é a luta da [??]. ${ }^{4}$ Senão, nada adianta.

Júlia: Mas a gente não tem essa luta travada com os meninos, Celo. Porque, com os meninos, é um processo. É um processo de desenvolvimento dos meninos e que os meninos vão experienciar vários momentos da luta. Eles vão discutir o problema lá da casa, lá, vamos dizer, de limpar o Lago, como uma vez. Vamos fazer isso e vamos participar também da marcha dos catadores, que era perto do dia do meio ambiente, não-sei-o-quê, para a questão do meio ambiente, para experienciar na formação do tal do ator político. Até porque a gente não está formando os meninos para os meninos ser A, ser B, ser D. A gente está formando pessoas com senso crítico para formular novos projetos de vida porque os meninos são seres em desenvolvimento. Você não pode pegar o menino e dizer: "Olha, é isso aqui". Ele tem de ir lá na marcha, tem de ver se é isso que ele quer. Já teve menino que já disse: “Ah, Jú, eu não quero isso para a minha vida não. Eu quero é estudar. Não quero ficar marchando não. E pegando sol na moleira!". Eu disse: "Ótimo, lindo. É isso mesmo, não pega isso não”. Então, não é o Movimento como sindicato, como movimento de classe, não tem isso. É um Movimento diferente de formação de crianças e adolescentes. Essa era a nossa metodologia. O

4. Nesse e nos próximos exemplos, utilizo [??] para indicar a ausência de uma palavra ou expressão cuja transcrição não foi possível. 
que aconteceu com o Movimento é que o Movimento, ele foi um ator político numa época muito importante. Então o Movimento, ainda hoje quem vê falar do Movimento, tem na cabeça esse Movimento. É um Movimento muito grande na cabeça e no seu propósito, mas as suas pernas são mínimas para andar a para aguentar essa cabeça. Então a pressão política, ela é muito forte. Como é que você vai dizer que nós não vamos para o Congresso? Como é que você vai dizer que você não vai na luta do rebaixamento penal, contra o rebaixamento da idade penal? Como é que você vai... você entendeu?

Paula: O que ele está questionando é os outros estados não assumirem isso.

Júlia: Os outros estados, Celo, não tem a...

Marcelo: (...) E, às vezes, a gente ia, ia só ficar com esses protestos, e acaba que não traz a discussão para cá. E acho importante, por exemplo... Tia Jú, eu entendo que a gente não está formando aqui como miliante em quantidade. Mas, que o guri, no momento em que ele passa a ter uma oficina nossa, daqui a pouco, ele visualiza dentro de uma discussão do passe livre, ele, por pernas próprias, vá até lá e vá porque ele teve uma formação. E daqui a pouco, por ele querer, pega e abandona o Movimento e vai lá, se torna um representante. Aqui é o meu grupo. É nesse sentido. E isso que está faltando, a gente acaba fazendo projetos amplos e acaba não trazendo esses nacionais para o nosso regional. É isso que eu estou falando. A gente vai para as marchas contra a corrupção e a favor do Lula, mas aí não entra numa marcha contra o Roriz aqui no Distrito Federal.

Nesse trecho, o tema do debate é o envolvimento da Comissão Local do DF em questões nacionais - por sua proximidade com o centro do poder político, o MNMMR/DF estaria assumindo funções da iniciativa nacional, o que prejudicaria sua atuação local. O trecho destacado em (2) refere-se especificamente à participação em 
manifestações de caráter nacional - marchas do MST e do Movimento Nacional de Catadores - para a experiência do protagonismo. Na representação de Júlia acerca do protagonismo juvenil, há um corte entre o protagonismo como ‘intervenção', ação prática por mudança social, e como experiência de um espaço de participação. Para a educadora, o objetivo do Movimento em termos de protagonismo juvenil é possibilitar a experiência da participação, da cidadania pelo manifesto. Marcelo discorda do efeito dessa vivência "do ator político" para a formação de protagonistas; para ele, o protagonismo está ligado a ação, intervenção e autonomia. Vejamos o Quadro 1 a seguir:

Quadro 1 - Negociação do significado de 'protagonismo juvenil' na Reunião 1

\begin{tabular}{|c|c|}
\hline PROTAGONISMO PARA JÚLIA & $\begin{array}{l}\text { PROTAGONISMO } \\
\text { MARCELO }\end{array}$ \\
\hline $\begin{array}{l}\text { "Não era que os meninos fossem intervir" } \\
\text { "era dos meninos experimentarem o } \\
\text { protagonismo juvenil" } \\
\text { "que os meninos pudessem vivenciar esse } \\
\text { ator político" } \\
\text { "como exercício de cidadania" } \\
\text { "os meninos vão experienciar vários momentos } \\
\text { da luta" } \\
\text { "para experienciar na formação do tal do ator } \\
\text { político" }\end{array}$ & $\begin{array}{l}\text { "Mas, que o guri, no momento } \\
\text { em que ele passa a ter uma } \\
\text { oficina nossa, daqui a pouco, } \\
\text { ele visualiza dentro de uma } \\
\text { discussão do passe livre, ele, por } \\
\text { pernas próprias, vá até lá e vá } \\
\text { porque ele teve uma formação." }\end{array}$ \\
\hline
\end{tabular}

Na negociação sobre o papel de protagonistas e as atitudes que devem caracterizar o protagonismo juvenil, há uma discordância entre Júlia e Marcelo. Na representação de Júlia, nota-se um corte entre participação e ação: o protagonismo, para Júlia, está representado no nível da participação, não no nível da ação ("não era de que os meninos fossem intervir"). Em termos dos processos verbais implicados na representação do protagonismo por Júlia, há a recorrência do mundo da experiência - 'experimentar', 'vivenciar', 'experienciar' - denotando 
o protagonismo como exercício de aprendizagem. Para Júlia, então, o significado de protagonismo juvenil refere-se à participação como exercício.

Marcelo discorda e texturiza sua discordância com o adversativo 'mas', no início do trecho destacado na coluna da direita do Quadro 1. Em sua representação, o protagonismo refere-se ao campo da ação - representada em termos de um exemplo de atuação concreta em uma luta específica, a do passe livre para estudantes em transporte coletivo. Para Marcelo, a experiência que caracteriza o protagonismo na representação de Júlia é apenas parte do processo que desemboca na ação protagonista - "e vá porque teve uma formação". Além da perspectiva agentiva do protagonismo, outro aspecto do significado de protagonismo juvenil evidenciado na representação de Marcelo é a autonomia ("por pernas próprias").

Para Marcelo, o corte entre participação/ação, no debate em torno do protagonismo juvenil, parece relacionar-se às escalas de atuação. Esse será nosso foco na próxima seção.

\section{Protagonismo e escalas de atuação}

A discussão em torno das escalas de atuação no âmbito do Movimento desdobra-se em duas relações entre local e nacional. $\mathrm{Na}$ primeira, debate-se a questão de a Comissão Local do Movimento no DF assumir o papel da iniciativa nacional do MNMMR em ações voltadas ao Congresso Nacional. Na segunda, o debate volta-se para a necessidade de uma ação integrada entre as diversas comissões locais do Movimento nos estados. Vejamos a primeira faceta dessa discussão no exemplo (3) a seguir:

(3) Marcelo: Eu acho que a gente poderia iniciar a fala [na Assembléia Nacional do MNMMR] tentando trazer isso: o que é o escritório do Distrito Federal em termos de Movimento porque acaba acontecendo isso, a gente acaba fazendo análise de conjuntura nacional, fica fazendo 
análise social nacional e não faz o regional, que a gente que passa batendo na tecla, que os caras acham que Brasília, que aqui é para a gente ficar pensando os problemas do Congresso Nacional. E aí é o que a gente vê com os guris, quando a gente vai fazer um trabalho, os guris pensam governo, o governo deles é o Lula. Não é a Câmara Legislativa, não é o Roriz!

Paula: Parece que o Roriz é fato.

Júlia: Não, o Roriz é um administrador!

Paula: Mas não é por causa da infra-estrutura do Nacional essa conjuntura de Brasília não.

Marcelo: Não, eu não estou falando isso. Eu só estou puxando para que a gente tem que se atentar para isso.

Júlia: Brasília, realmente, na luta de criança e adolescente acontece é aonde? Dentro do Congresso. Era lá que nós estávamos mesmo. E estamos ainda.

Marcelo: Tia Jú, não. Isso era necessário. O problema daí é questão de lei. É a [??] que é lei nacional. É pelo Congresso. Não estou falando isso. Eu estou falando em que a nossa luta aqui muitas vezes, em vez de estar indo de frente com o governo distrital, está mais se envolvendo com questões nacionais. É isso que eu....

Paula: Eu acho que, por exemplo, os estados todos têm que se envolver com as questões nacionais.

Marcelo: Justamente! E a gente fica de fora de outros movimentos que estão nascendo aqui no Distrito Federal e o Movimento acaba ficando de fora. É isso que eu quero pautar. [...]

Júlia: Mas eles não estão preocupados com isso não. Eu acho que o principal problema não é nem a confusão, por exemplo. Porque isso é uma confusão política mesmo. E também de interesse nosso mesmo. Porque, por exemplo, quando a gente participava, qual é a nossa proposta? Não era de que os meninos fossem intervir. A proposta dos meninos era dos meninos experimentarem o protagonismo 
juvenil e que os meninos pudessem vivenciar esse ator político. Então, por isso, que a gente participava das manifestações nacionais. Por quê? Como espaço de participação. Muitas vezes, a gente, ora, já foi na marcha do MST com os meninos, na marcha da educação, mas como exercício da cidadania, para aprender isso. Tanto faz a gente aprender isso na marcha do MST, como aprender aqui na Câmara Legislativa. Para nós, era indiferente isso. Isso era uma questão metodológica.

Marcelo: Mas o protesto nacional pode acontecer, mas tu tem que trazer ele para o teu estado também.

Júlia: Nem sempre você consegue trazer.

Marcelo: Eu sei que não! Mas essa é a luta da [??]. Senão, nada adianta. [...]

Marcelo: (...) E, às vezes, a gente ia ia só ficar com esses protestos, e acaba que não traz a discussão para cá. E acho importante, por exemplo... Tia Jú, eu entendo que a gente não está formando aqui como miliante em quantidade. Mas, que o guri, no momento em que ele passa a ter uma oficina nossa, daqui a pouco, ele visualiza dentro de uma discussão do passe livre, ele, por pernas próprias, vá até lá e vá porque ele teve uma formação. E daqui a pouco, por ele querer, pega e abandona o Movimento e vai lá, se torna um representante do Movimento. Aqui é o meu grupo. É nesse sentido. E isso que está faltando, a gente acaba fazendo projetos amplos e acaba não trazendo esses nacionais para o nosso regional.

Nesse excerto, o que está em foco, e se representa como um problema, é o fato de a Comissão Local assumir a tarefa de representação política do Movimento junto ao Congresso Nacional e em manifestações públicas de caráter nacional. A oposição entre as escalas nacional e local é texturizada em dualidades como nacional/ regional, Congresso Nacional/Câmara Legislativa, Lula/Roriz , como ilustra a Figura 1: 
Congresso Nacional

Lula

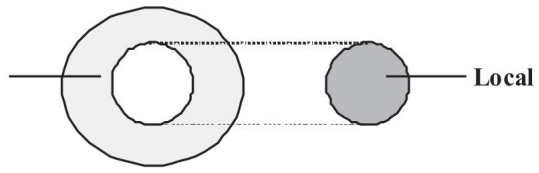

Câmara Legislativa

Nacional

Figura 1 - Escalas nacional e local como oposições

Nessa primeira parte da discussão, as escalas nacional e local são texturizadas como oposições: há uma relação de contraste entre elas. Marcelo introduz essas oposições no debate, ressaltando que a atuação da Comissão Local do DF em questões e mobilizações de cunho nacional dilui o pertencimento a um contexto local, influenciando os modos como os/as meninos/as do Movimento entendem a conjuntura política ("o governo deles é o Lula (...), não é o Roriz”). A responsabilidade por esse estado de coisas é atribuído, por um lado, à iniciativa nacional do MNMMR ("os caras acham que Brasília, que aqui é para a gente ficar pensando os problemas do Congresso Nacional”). Embora isso seja enunciado de modo indefinido, Paula recupera o significado de "os caras" como sendo a iniciativa nacional, e nega a relação de responsabilidade construída por Marcelo: "mas não é por causa da insfra-estrutura do nacional essa conjuntura de Brasília não". Por outro lado, há uma responsabilização das outras comissões locais por não tomarem para si a tarefa de atuação nas demandas de caráter nacional, partilhando-a com a Comissão Local do DF ("os estados todos têm que se envolver com as questões nacionais”). A divisão da tarefa, nesse caso, é modalizada como obrigatoriedade.

Entretanto, a proximidade com o centro do poder leva a Comissão Local do DF a assumir a representação política do MNMMR em instâncias de luta no Congresso Nacional - nas manifestações de 18 de maio contra a exploração sexual de crianças e adolescentes; no debate contra o rebaixamento da maioridade penal; junto às frentes parlamentares que apoiam a causa da luta em favor dos direitos de crianças e adolescentes etc. Para Júlia, essa "confusão" de escalas de atuação deve-se também a um interesse próprio da 
Comissão Local do DF na participação em manifestações junto ao Congresso ("de interesse nosso mesmo"). Sua justificativa é expressa explicitamente na superfície textual ("por isso a gente participava das manifestações nacionais. Por quê? Como espaço de participação”). Com a justificativa da participação, Júlia desconstrói a oposição entre as escalas de atuação do Movimento levantada por Marcelo: "Tanto faz (...). Para nós era indiferente isso”. Essa indiferença pauta-se no corte entre ação e participação - se o objetivo da atividade não é intervir, mas apenas experienciar a mobilização, então de fato não faz diferença a natureza da marcha em termos de escala.

Mas o significado de protagonismo juvenil defendido por Marcelo refere-se à ação autônoma, e nesse caso a diferença de escalas pode ter implicações, uma vez que pequenos grupos autônomos têm mais condição de transformar em primeira instância realidades locais, vinculadas a problemas locais imediatos, que ter efeito em lutas mais amplas. Daí as modalidades deônticas em "Mas o protesto nacional pode acontecer, mas tu tem que trazer ele para o teu estado também”. Enquanto a participação em manifestações de cunho nacional é modalizada como possibilidade, sua aplicação aos contextos mais imediatos recebe modalidade de obrigatoriedade. Esse sentido se completa em "Senão nada adianta".

Começa a se delinear aí uma perspectiva não tanto de oposição entre as escalas, mas de complementaridade. A relação entre as escalas nacional e local é texturizada na recorrência de orações com 'trazer' "tem que trazer ele [o protesto nacional] para o teu estado também”, "acaba que não traz a discussão para cá”, "acaba não trazendo esses nacionais para o nosso regional” -, como ilustra a Figura 2:

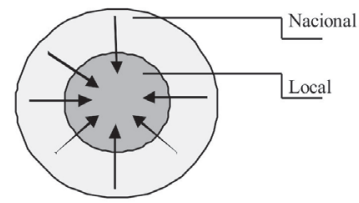

Figura 2 - 'Trazer' o nacional para o local 
Essa representação com 'trazer' sugere uma perspectiva espacial dentro/fora, em que dentro se identifica com o local e fora com o nacional. Esse sentido se completa no uso dos dêiticos de proximidade com o contexto local ("aqui no DF", "pra cá", "aqui é o meu grupo”) e da metáfora espacial 'ficar de fora' (de movimentos mais locais, em decorrência da escala de atuação do Movimento). Assim, nas representações de Marcelo, a participação nas instâncias nacionais de manifestação se justifica na medida em que tem efeitos na mobilização pela transformação local. As setas na Figura 2 apontam apenas em um sentido - de fora para dentro - uma vez que a perspectiva é da influência da atuação em escala nacional no contexto local.

A relação entre as escalas nacional e local, entretanto, se complexifica no outro aspecto do debate acerca das escalas de atuação do Movimento, aquele relacionado à ação integrada das diversas comissões locais do MNMMR. Esse tema é lançado em debate quando se aborda o posicionamento que a Comissão Local do DF assumiria na assembleia nacional em relação à atuação do Movimento junto a meninos e meninas efetivamente em situação de rua:

(4) Marcelo: Por exemplo, olhe o nome do Movimento: Movimento de Meninos e Meninas de Rua. Você não discute mais a questão dos meninos de rua, parece que...

Maria: Virou comum os meninos de rua! É normal.

Marcelo: É normal. O Movimento não está nem integrado com a questão da discussão do tráfico! (...) O problema é esse, a gente tinha que estar integrado junto com o movimento, indo para o lado das favelas, tinha que estar integrado... não está.

Vera: Da moradia.

Marcelo: De moradia.

Júlia: Marcelo, aqui quem veio dar uma chamada em mim literalmente foi um menino. O menino que passou aqui, veio aqui e disse: "Ô Jú, eu estou a fim de fazer um trabalho aí, mas é com os meninos de rua porque eu fui menino 
de rua e eu sei a importância que foi o Movimento. E o Movimento não está trabalhando com esses meninos mais". (...) Não, nós estamos completamente sem um eixo!

Marcelo: Mas daí é um posicionamento que a gente tem que ter nessa assembleia.

Paula: Na assembleia nós não vamos ter isso.

Marcelo: Mas, se a gente vai propor uma descentralização jurídica e administrativa, nós [??] para isso também!

Júlia: Não. Não vai, sabe por que, Celo? Aí, os estados vão ter autonomia, o Distrito Federal vai ter autonomia de pensar metodologicamente o que o Movimento deveria fazer. Marcelo: E adianta isso se no Brasil inteiro tem menino na rua?

Maria: Mas a gente vai estar...

Marcelo: Maria, isso é ilusão! Nós só vamos se fortalecer quando nós articularmos a nossa luta a nível nacional. Porque, do mesmo jeito que tem o menino aqui na rua, tem lá na rua [??], tem em São Paulo.

Quando se aborda a questão do escopo do Movimento, em termos da atuação direta com crianças e adolescentes efetivamente em situação de rua, surgem, por um lado, a preocupação com a articulação com outros problemas em escala local - o tráfico de drogas na região e a questão da defasagem de unidades domiciliares - e, por outro lado, a necessidade de trabalho integrado com outras comissões locais do MNMMR no enfrentamento do problema da situação de rua entre crianças e adolescentes no País.

Embora Marcelo tivesse se posicionado a favor de uma atuação mais local do Movimento no DF, reclama a necessidade de integração entre as diversas comissões locais para uma influência efetiva na questão da situação de rua. Quando Júlia sugere a descentralização do Movimento como autonomia para o trabalho da Comissão Local do DF na decisão acerca do escopo de atuação do Movimento, ele questiona a eficácia do trabalho isolado das outras iniciativas locais, sugerindo que se levasse o problema à assembleia nacional 
("nós só vamos se fortalecer quando nós articularmos a nossa luta a nível nacional”), com uma estrutura linguística 'só/quando' que indica a representação da integração entre as esferas locais como necessária.

Assim, a relação entre as escalas de atuação no âmbito do Movimento ganha contornos mais complexos, o que se mostra relevante nas representações de duas maneiras: (i) a atuação local do Movimento no DF seria fortalecida pela participação em debates de cunho nacional se esses debates fossem trazidos para os contextos e os problemas locais, inclusive com a articulação com outros movimentos sociais locais; (ii) as diversas comissões locais do Movimento deveriam agir de forma integrada de modo que, cada qual atuando em seus contextos específicos, pudessem ter juntas eficácia na transformação da conjuntura mais ampla.

Isso está de acordo com as caracterizações de Gohn (2003a) e Castells (1999) sobre os novos movimentos sociais como movimentos descentralizados mas articulados em redes, e denuncia a ineficácia da rede formada pelas comissões locais do Movimento. Essa perspectiva da relação entre as escalas nacional e local poderia ser representada conforme a Figura 3:

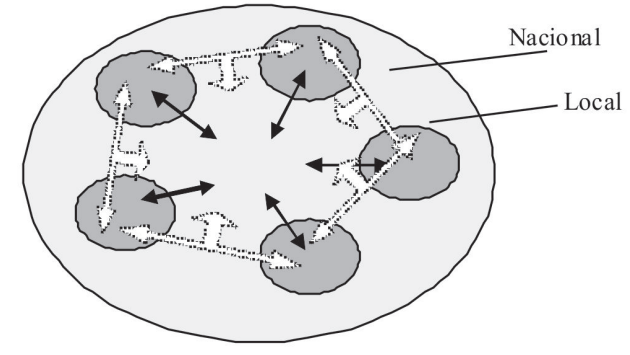

Figura 3 - Relação dialética entre as escalas nacional e local 
De acordo com a Figura 3, estabelecem-se relações de mãodupla entre as escalas nacional e local - no sentido de que (i) a configuração da escala nacional influencia a escala local e a atuação na escala local, quando integrada em rede, causa alterações na configuração da escala nacional, e (ii) uma articulação entre as atuações nos diversos âmbitos de escala local pode se configurar um instrumento de transformação da conjuntura nacional. A primeira relação é representada na figura pelas setas pretas e a segunda pelas setas brancas pontilhadas.

O que está em jogo aqui é a problemática organizacional do Movimento - o modo como se configuram as comissões locais e a iniciativa nacional, e os modos como agem para atingir seus objetivos comuns. Talvez seja esse um dos grandes empecilhos para a ação efetiva do Movimento e também o problema de mais difícil solução, uma vez que demanda habilidade administrativa/organizacional e recursos que possibilitem fazer funcionar essas engrenagens.

\section{Algumas considerações}

A análise das modalidades subjetivas/objetivas utilizadas por Júlia e Marcelo no recorte da reunião sugere assimetrias em termos interpessoais. Essas assimetrias podem ser relacionadas ao sistema de hierarquias interno ao Movimento: Júlia adota postura mais afirmativa, marcando posição de autoridade; Marcelo mitiga a discordância, busca pontos de consenso e texturiza o dissenso com modalidades. $\mathrm{O}$ modo como as diferenças são negociadas é mediado pela hierarquia, o que pode se relacionar a certa imobilidade de papéis e implicar um empecilho para mudanças no âmbito do Movimento.

$\mathrm{Na}$ discussão acerca do significado de protagonismo juvenil, Júlia representa um corte entre participação e ação - o protagonismo juvenil figura no âmbito da participação como modo de experiência. $\mathrm{O}$ foco de discordância é que Marcelo situa o significado de protagonismo no campo da ação, da mobilização autônoma. A análise dos tipos de 
processos verbais utilizados em uma e outra representação é útil para se perceber tanto o corte quanto as diferenças entre os significados de protagonismo juvenil em cada uma delas.

O corte identificado entre participação e ação liga-se ao debate em torno das escalas nacional e local em termos da atuação do Movimento. Três tipos de relação são estabelecidas entre as escalas nacional e local no debate. Essas relações organizam-se num crescendo de complexidade: primeiro, as escalas nacional e local são texturizadas como oposições - no debate acerca da atuação da Comissão Local do DF em temas de âmbito nacional -, o que se evidencia no léxico pela construção de dualidades; segundo, estabelece-se uma relação de mão única entre as duas escalas de atuação, no sentido nacional-local - em referência ao aproveitamento de experiências de mobilização nacional em contextos locais -, o que se realiza linguisticamente em metáforas espaciais com 'trazer'; terceiro, quando se aborda a questão do escopo do Movimento e da necessidade de ação integrada entre as diversas comissões locais do Movimento, a relação entre as escalas se complexifica, configurandose em uma relação de mão dupla.

A impressão que se tem é que a iniciativa nacional apenas existe no papel e na imagem projetada no ideal de seus membros. Quando participei da Assembléia Nacional do MNMMR em 2006, anotei em meu diário de campo: "Na verdade, o Nacional não existe! O Nacional não passa de uma casa com uma funcionária que faz tudo!". Daí a Comissão Local do DF precisar assumir as tarefas que deveriam ser do Movimento Nacional. Além disso, a realização das assembleias nacionais é um dispositivo demasiado oneroso - para ser realizado com a periodicidade que seria adequada. Parece-me que duas soluções poderiam facilitar, por um lado, a eficiência da Iniciativa Nacional e, por outro, a comunicação entre as diversas comissões locais. A primeira, mais custosa em termos financeiros, dependeria de aprovação de projeto de captação de recurso que incluísse gastos com a contratação de um/a coordenador/a executivo para a Iniciativa Nacional, sediado/a em Brasília. Isso implicaria a necessidade de uma reformulação no estatuto do Movimento, 
já que pelo estatuto vigente o cargo de coordenação precisa ser voluntário. A segunda, mais fácil, consiste simplesmente na criação de mecanismos de comunicação baseados nas tecnologias digitais (listas de discussão com mediação que facilitassem a persecução de objetivos propostos; grupos de trabalho ligados pela Internet para a abordagem de problemas específicos; teleconferências que lançassem mão dos softwares gratuitos disponíveis para esse fim) que possibilitassem comunicação constante das coordenações locais entre si e com a coordenação nacional. Isso requer poucos recursos já que as comissões locais já contam com computadores conectados à Rede - mas algum esforço por parte de todas as comissões locais.

Trata-se de uma questão discursiva no sentido de que envolve a necessidade de apropriação de recursos discursivos, como a habilidade para utilizar as ferramentas próprias desse tipo de comunicação. A discussão em torno das escalas de atuação do Movimento também está relacionada a sua articulação em rede, no sentido de formulação de ações estratégicas e de manutenção do foco em um objetivo comum: atuação local das iniciativas articuladas em rede para um fortalecimento das demandas do Movimento em nível nacional. Para isso é necessária a conquista de uma articulação eficiente, que dependeria de intensa comunicação entre seus membros.

Recebido em: maio de 2010

Aprovado em junho de 2010 viviane.melo.resende@gmail.com

\section{Referências bibliográficas}

CASTELLS, M. O poder da identidade. Trad. K. B. Gerhardt. São Paulo: Paz e Terra, 1999. 
CHOULIARAKI, L. \& N. FAIRCLOUGH. Discourse in late modernity. Rethinking critical discourse analysis. Edinburgh: Edinburgh University Press, 1999.

FAIRCLOUGH, N. Discurso e mudança social. Trad. I. Magalhães. Brasília: Editora Universidade de Brasília, 2001.

Analysing discourse. Textual analysis for social research. London: Routledge, 2003.

FREGNANI, I. Cartilha grupo de adolescentes do Movimento Nacional de Meninos e Meninas de Rua. Florianópolis: MNMMR/SC, 1992.

GOHN, M. G. Apresentação. In: M. G. Gohn (org.). Movimentos sociais no início do século XXI. Antigos e novos atores sociais. Petrópolis: Vozes, 2003a. pp. 7-10.

Movimentos sociais na atualidade: manifestações e categorias analíticas. In: M. G. Gohn (org.). Movimentos sociais no início do século XXI. Antigos e novos atores sociais. Petrópolis: Vozes, 2003b. pp. 13-32.

HALLIDAY, M.A.K. An Introduction to Functional Grammar. $3^{\text {rd }}$ ed. revised by C. M. I. M. Matthiessen. London: Arnold, 2004.

HAMMERSLEY, M. Introducing ethnography. In: D. Graddol et al (orgs.). Researching language and literacy in social context. Clevedon; Philadelphia; Adelaide: The Open University, 1994. pp.1-17.

MASON, J. Mixing methods in a qualitative driven way. Qualitative Research, 6 (1), 2006: 9-25.

PASQUINO, G. Movimentos Sociais. In: N. Bobbio; N. Matteucci; G. Pasquino. Dicionário de política. Trad. C. Varrialle et al. Brasília: Editora Universidade de Brasília; São Paulo: Imprensa Oficial do Estado de São Paulo, 2004. pp. 787-92.

RESENDE,V. M. Análise de Discurso Crítica e Etnografia: o Movimento Nacional de Meninos e Meninas de Rua, sua crise e o protagonismo juvenil. Tese de doutorado (Linguística). Brasília: Universidade de Brasília, 2008.

Análise de Discurso Crítica e Realismo Crítico: implicações interdisciplinares. Campinas: Pontes, 2009.

RESENDE, V. M. \& V. RAMALHO. Análise de Discurso Crítica. São Paulo: Contexto, 2006. 
RETAMOZO, M. Esbozos para una epistemología de los sujetos y movimientos sociales. Cinta de moebio, 26, 2006. Facultad de Ciencias Sociales. Universidad de Chile. Disponível na Internet. <http://www.moebio.uchile. cl/26/retamozo.htm>. Acesso em 25 fev. 2007.

SANTOS, B. R. MNMMR - uma trajetória de luta e trabalho em defesa da criança e do adolescente no Brasil. São Paulo: MNMMR; UNICEF, 1994. 